\title{
On the Nature of Talk-in-Interaction: A Pragmatic Study of Informal Conversations
}

\author{
By Justine Bakuuro* \& Damasus Tuurosong ${ }^{+}$
}

\begin{abstract}
This study attempts to uncover what the recurring patterns of interaction in informal conversations are. It is also interested in finding out which recurring patterns of interaction dominate in informal conversations and how these recurring patterns of interaction play out in informal conversations. Data used in the study includes only recordings of naturally occurring conversations of close friends in informal settings. The researcher meticulously transcribed the data using the conventions proposed in the Jefferson Notation System. In Conversation Analysis (CA), transcription is part of data analysis. The transcription/analysis reveals that four main recurring patterns characterize informal conversations among friends: Adjacency Pairs, Topic Change, Figurative Language and Dysfluency. The study further reveals the fact that Adjacency pairs is a very dominant recurring pattern in friendly informal conversations. As a form of turn-taking, Adjacency pairs largely characterized the conversations compared to the other three recurring patterns. Finally, the study underscores the fact that friendly informal conversations stay focused on selected topics with very little or no change of topic. Mid-way between the little or no topic change and the dominance of Adjacency pairs are dysfluencies and rhetorical questions.
\end{abstract}

Keywords: conversation analysis, recurring patterns, informal conversations, Jefferson notation system

\section{Background}

Language use in social interaction is the crust of the matter in typical Conversation Analysis studies. Havey Sacks is a pioneering scholar in this field of discourse studies as CA traces its roots to him (Wooffitt 2001). Sacks recorded and analysed how people actually converse in typically ethnographic manner. It must be stated that a myriad of studies have been done in this area since the 1960's by Havey Sacks and Gail Jefferson among other Discourse scholars. However, different concepts and assumptions on conversation analysis (CA) have been used. Hutchby and Wooffitt have defined CA as "...the systematic analysis of the talk produced in everyday situations of human interaction: talk-in-interaction" (1998, p. 13). In the same way, Havey (1999) points out that CA is generally referred as "...the analysis of utterances produced in daily communication..." CA focuses not only on language produced by people in talk-in-interaction, but also on the understanding and interpretation of the speakers of each other's utterances during

\footnotetext{
*PhD Candidate \& Lecturer, Department of African and General Studies, SD Dombo University of Business and Integrated Development Studies, Ghana.

${ }^{+}$Senior Lecturer \& Head, Department of African and General Studies, SD Dombo University of Business and Integrated Development Studies, Ghana.
} 
the talk itself (Hutchby and Wooffitt 1998). Additionally, when analysing data, characteristics like culture, gender and social background have to be considered (Sacks 1992). Indeed, these factors are what make every CA study unique despite the commonality of applying transcription conventions laid down by lead scholars in the field, notably Gail Jefferson. These factors have been briefly touched on as the social milieu, age, economic status and ethnic backgrounds of the participants have been described to put the findings and conclusions in proper perspective.

Regarding data analysis, Atkinson and Heritage note that analysts are not expected to interpret the participants understanding in utterances or to restrict them during the recording of the data interaction. They are, instead, required to present the data based on their own observation of the participants' ordinary behaviour throughout the interaction (Atkinson and Heritage 1984).

The first section looks at the methodology of collecting data such as participants, context, and the recording itself. The second section looks at several points in transcription procedure and system used in analysing the record data and brief definitions of CA elements discussed in the data analysis. Moreover, a range of symbols that exists in transcription will be introduced as well. The third section is data analysis of a series of actions within utterances. However, this paper tends to limit the discussion to particular aspects in conversation analysis. The aspects consist of turn-taking, topic change, preference organization, listing, use of figurative language, face saving, breakdowns and repairs and dysfluency. The focus is on these aspects as they are the commonly associated parameters in doing pragmatic CA studies such as this.

\section{Problem/Justification}

In conducting a scientific study on conversation analysis, the researcher usually begins by setting up a problem connected with a preliminary hypothesis. Generally, many language users, including us, believe that patterns usually recur in both formal and non-formal conversational interactions. It is also believed that recurring patterns of interaction vary between formal and informal conversations when it comes to their dominance in speech. Language users also hold the view that the manner of manifestation of recurring interactional patterns vary between formal and informal conversations. It is against the backdrop of these assumptions that this study is conducted to investigate the extent of accuracy and veracity of these ground assumptions. Whilst many studies may have been conducted in this regard, the socio-economic and cultural demographics that have been spelled out in the Methodology clearly sets out the gap in this study to be filled. That is to say, how does the manner of manifestation of recurring interactional patterns of informal conversations of employed, married adult-male graduates (educated) of the Dagaare ethnic extraction of northern Ghana play out? Admittedly, many studies in CA have been conducted on informal conversations just like this study as has been stated in the introduction above. However, the hypotheses laid down for investigation, the setting, as well as the research participants always vary, giving each a touch of uniqueness (in this case, as in the socio-economic 
demographics outlined above) and hence a gap to fill up in this research area. Simply put therefore, the problem under investigation here is to find out the veracity and or accuracy of these assumptions as it pertains to the unique subjects in this study. The study would thus provide for contrastive comparisons between and among similar studies and that may occasion the basis for further studies in this regard.

\section{Questions}

1. What are the recurring patterns of interaction in informal conversations?

2. Which recurring patterns of interaction dominate in informal conversations?

3. How do recurring patterns of interaction play out in informal conversations?

\section{Assumptions}

This study operates on the following hypothetical assumptions:

a. That interactional patterns usually recur in non-formal interactions;

b. That particular recurring patterns usually dominate in informal conversations;

c. That recurring interactional patterns manifest themselves in particular ways in informal conversations.

\section{Theory}

This is fundamentally a descriptive qualitative study, employing the use of quantitative methods. It therefore lends itself to a number of theories in language study including theories in the field of pragmatics, Conversational studies, ethnography and content analysis, among others.

It is however anchored strongly by the Discourse theory within the larger field of Pragmatics and Discourse Studies. Indeed, as earlier indicated, a central focus of discourse analysis is Conversation Analysis.CA is therefore at the centre of oral discourse analysis (Hoey and Kendrick 2017). In general, discourse theory is concerned with human expressions, often in the form of language. It highlights how such expressions are linked to human knowledge. In other words, discourse theory is concerned with questions of power and often with questions of institutional hierarchies. In this study, the exchanges between speakers reveal to us the question of power and human relations among the speakers by way of the expressions used. Under very normal circumstances, this is not the case in informal conversations among friends in an informal setting such as we have in this study. But the reason for this may be due to the socio-cultural background of the research participants. Among the Dagaaba of northern Ghana (as it is with many other northern Ghana ethnic groups),age and position is highly respected, to the extent that even in typically informal situations, respect for the elderly and authority is marked. This is conveyed by the four main identifiable patterns which characterise the three conversations: adjacency pairs, topic change, figurative 
language and dysfluency. To this extent therefore, the study is anchored theoretically by the Discourse theory in general but with a narrowed focus on Critical Discourse studies.

\section{Literature Review}

By the nature and character of this study, relevant literature hinges around the following key CA dimensions: turn-taking, topic change, preference organization, listing, use of figurative language, face saving, breakdowns and repairs, and dysfluency. The study will thus focus on these aspects in the analysis. As indicated earlier (see end of Background), the focus is on these aspects as they are the commonly associated parameters in doing pragmatic CA studies such as this.

\section{Turn-Taking}

Turn-taking is fundamentally the driving force of every conversation event. Based on Sacks's work in collaboration with two of his colleagues in the 1960s on turn-taking, Beattie (1983) categorizes three techniques in indicating the turntaking system in CA. First is the technique called 'previous speaker select next' which happens if the previous speaker addresses a question directly to someone to be answered and being a next speaker. It could be either by straight calling his/her name or using a nonverbal sign such as gaze or gesture toward the person who is selected to be the next speaker. Second is the "self-select" technique which means that people gain their own turns by initiating utterance in a talk. Lastly, the utterances are continued by the current person because the next speaker is not selected and no one tries to gain the right to speak, according to Beattie (1983). Have then explains that one of these categories comes before another systematically. It means that the select-next speaker is followed by self-selection and self-continuation techniques respectively (Havey 1999).

\section{Preference Organisation}

The structure of preference is signed by a first part in utterances that consist of several action sequence pairs such as assessment, invitation, offer, proposal and request. The adjacency pairs discussed in $\mathrm{CA}$ is involved within sequences to examine the coherence of actions between utterances (Nur 2014). In one chapter of her discourse analysis book, Wooffitt (2001) states, for example, that it is understood that a question from the previous speaker should be followed by an answer, an offer could be accepted or declined, an invitation could be possible followed by an acceptance or a refusal, etc. 


\section{Use of Figurative Language}

Only few specific studies have been done on the use of figurative language in conversation (Fussel and Kreuz 1998). The common figurative expressions used by people in a conversation are rhetorical questions, idioms, metaphor and irony.

\section{Topic Change}

Conversations are controlled by changing from one topic to another naturally. It often cannot fully be predicted when the topic will be changed. The topic change, however, appears when one of the speakers introduces a new topic which is then agreed by the interlocutors (Seedhouse 2004).

\section{Face Saving and Listing}

Face saving is often defined as an action done by people to save theirs or others' position, idea, or assumption (Yun 2006). Face-saving in conversation has a strong relationship with politeness (Holtgraves 1992). This is categorized in two terms by Brown and Levinson; positive and negative faces. Negative face is defined as a personality of someone who protects and prevents his right and freedom to do something on his own willingness. Positive face is an action done by speaker in attempting positive self-image without contrasting with others (Brown and Levinson 1978).

As regard listing, it is a common thing occurs in a conversation. It happens very often when the speaker left the last item of the list in the blank way. The listing, however, is more specific when it is used in formal political speech in order to attract people's attention (Heritage and Greatbatch 1986).

Scholars such as Wardhaugh (2006), Mey (2001), Leech (1981) and Yule (2010), among others, identify two types of face: positive face and negative face. Simply put, positive face is the desire to win the approval of others; while negative face is the desire to be unimpeded by others in one's actions.

\section{Breakdown and Repair}

Breakdown is linked to misunderstanding, obvious mistake in interaction, or just an expression of doubtfulness. Breakdowns are often followed by repairs which are divided into several categories; "self-initiated self-repair, other-initiated self-repair, self-initiated other-repair and other-initiated other-repair" (Hutchby and Wooffitt 1998, p. 61). Repair is a crucial part in a conversation in avoiding and correcting misunderstanding. As the name suggests, repair is the mechanism by which broken down conversations are restored to avoid misunderstanding.

\section{Dysfluency}

Dysfluency often takes place in an informal situation in social interaction. The more informal the conversation, the more frequently it happens. It could be 
symbolized by providing unfinished sentences, repeating words, or even repeating parts of sentences. The dysfluency appears more often in two situations; when someone or a group of people speaks in another language and when someone speaks to people they are close to in their mother tongue (Hutchby and Wooffitt 1998).

\section{Methodology}

As mentioned earlier, a good conversation analysis begins by setting up a problem connected with a preliminary hypothesis. The problem under investigation in this study is linked to three generally prevailing hypothetical assumptions in the field of CA (see assumptions above). Also, the data used in CA is usually in the form of video or audio recorded conversations, collected with or without researchers' involvement, typically from a video camera or other recording devices in the space where the conversation takes place (e.g., a living room, picnic, or doctor's office).We collected our data using the Voice Recorder on an Infinix Hot 8 (Pro) Mobile phone. This device has very high voice recording quality as we tested it ahead of the data collection.

The research subjects in this study comprised four regular friends including one of us the researchers (corresponding author), all of whom are of the Dagaare ethnic extraction of northern Ghana. As Davis (1984) puts it, ethnicity is "...a critical socio-demographic factor in conversation studies..." The recording however does not include his utterances as he carefully avoided being part. In order that my not being part would not affect the interactions, I deliberately engaged myself doing other things such as walking to the waitress to order meat and drinks, going to urinate and greeting some people on other tables in the pub. This took away all possible suspicions by the participants against me, thereby making room for the collection of a truly naturally occurring data in the nature of conversation. Indeed, this was confirmed as participants expressed surprise when I told them I had recorded them, despite having told them earlier on and having had their permission to do so. We are all male adults, aged between 29 and 42 years with educational backgrounds of at least first degree. Big as this demographic range may be, the findings can conveniently be generalized since other demographics (socio-economic and cultural), are largely common to all participants. This bridges the age demographic gap substantially. As indicated earlier (Background), these social, cultural, gender and economic demographics are crucial in every CA study to better situate the study and clearly establish the gap that is to be filled by this study. We do meet quite regularly for purposes of socialization and sometimes to discuss pressing socio-economic or political issues. Our interactions are thus usually informal. We took a total of three recordings. One of the recordings was on current economic hardship in Ghana (3 minutes, 28 seconds); the other on marital issues (lasting 4 minutes, 13 seconds); and the third on political issues (lasting 3 minutes, 41 seconds). All three conversations were set in pubs at different locations at different times during the day. We managed in 
various ways not to be part of the conversations to avoid any possible personal biases on the data. How did we do this, being part of the group?

Our aim was to collect data of naturally occurring speech (Sacks 1972). To meet ethical standards, we discussed the impending research project with them two weeks earlier before commencement of the series of recordings. They gave us approval to use their conversations as data. On each occasion of recording the conversations, we usually put on the Infinix Phone voice recording device, put it somehow on the middle of the round table (occupying most of the frontal of my side of the table with my bottle of drinks, glass and a rubber file, deliberately to avoid suspicion arising from the position of my phone on the table) and leave the table to do some other activity such as urinating or requesting meat for our consumption. This we do, praying that incoming calls should not interrupt the recording process. Fortunately, on all three occasions, no incoming call interrupted the process. We consciously ensured that we sat away from noise in the pubs, so the recordings are all very clear. Find attached the audio recordings.

After the secret recordings, we told them about them and played the tapes to their hearing. They were shocked, saying they thought we were going to inform them at the point of recording and that we may be using a very conspicuous recording gadget like those used by Journalist and musicians. They however gave us approval to use to the recording as data of the study. This therefore validates the originality, reliability and empirical nature of this study.

We therefore went on to construct detailed transcriptions from the recordings, capturing as much detail as is possible (Jefferson 1972, Hepburn and Bolden 2017, Mondada 2019). After transcription, I performed an inductive data-driven analysis aiming to find recurring patterns of interaction as well as their manifestation and dominance in the conversation. Based on the analysis, we identified regularities, rules or models to describe these patterns, enhancing, modifying or replacing initial hypotheses as it were. While this kind of inductive analysis based on data exhibits is basic to fundamental work in CA (Frohlich and Luff 1989), this method is often supported by statistical analysis in applications of CA in some studies. This study applied this statistical dimension in the analysis. It therefore makes the study a descriptive semi-qualitative one as it employs both quantitative and qualitative analysis (mixed methods). Some tables and charts have been used to aid analysis. Data analysis in this study has been done in two phases: Phase I is the Transcription of recorded data; Phase II is the analysis of Research Questions based on transcribed data.

\section{Transcription Procedure}

In CA, data transcription is considered an integral part of the data analysis process (Levinson 1983). This process is cumbersome. There are several ways that are adopted by analysts in transcribing CA data. Havey (1999) states that while a number of analysts usually pick out only the clear utterances spoken by participants during interaction in a transcription in order to avoid confusion to the readers, best practice in CA demands that analysts capture every detail of sounds 
produced in the recording, whether it is audible, meaningful or meaningless, etc., without changing or correcting them. In other words, several analysts emphasize on the content of the conversation to the neglect of how the language has been used in its natural state. This compromises the quality of such studies as they become less empirical and ethnographic.

In this paper, the recorded data was transcribed based on dictionary spelling of English words as they are heard on the audio. Particular transcription conventions are used in conversation analysis. The transcription procedure adopted in this paper is a conventional one as propounded by Gail Jefferson, which has come to be known as the Jefferson Notation System.The Jefferson Notation System is a set of symbols, developed by Gail Jefferson, which is used for transcribing talk.

Before explaining some examples of sequences in the conversation, I will clarify the transcription convention I have chosen and adopted in my transcription. A range of these symbols is employed from Havey's book which were devised by Gail Jefferson and commonly used by analysts in current CA publications.

Pauses are notated by their length in seconds that is shown in brackets and the stressed words are underlined. Parts of the transcript that are symbolized by single left square bracket indicate the point of overlap. Equal sign is the symbol for indicating no gap between two lines. The arrows represent the higher or lower pitches in the utterances. Some non-verbal features such as laughter are shown within the square bracket. The colon indicates a long sound in a word. The angle bracket is employed to indicate fast speech. Moreover, small degree sign is used to indicate the part which is quieter than other parts in utterances (Havey 1999). The use of feedback is also added as the transcript notation, for example "yeah", "mm", "ok", and "well". In addition, commas and full stops are used in the transcription to reflect their normal function in written language only.

\section{Data Analysis}

The analysis of data in this study is done in two phases. Phase I shall be the transcription and coding of data. As mentioned earlier, transcription and coding of recorded conversations are an integral and arguably the most important part of the analysis process in any conversation study. Phase II shall respond to the research questions in the study by applying appropriate data from the coded transcription.

\section{Phase I: Transcription and Coding of Data}

Transcription of First Conversation (Economy) (Lasting 3 Minutes, 28 Seconds)

1P Cheap $\uparrow$ are you not in Gha:na?

2S Hmm....

3P $\quad$ Only big grammar=

4A $\quad=\uparrow$ Yea:h=

5S Ya $\quad$ Y

6A I don't know (.) if they believe in God. That's my problem (3)

7S $<$ me I don't even know what to say> 
8P $\quad$ Oh $\uparrow[$ laugh $]$

9S Tweaaa (.) [laugh] $\neq$

10A I bought mine n:4200 Ghana plus number plate $\uparrow$ problem [laugh] Together[laugh]

11A Then you are even better. Do you know (.) the cost of mine $\uparrow ?$ ?...stop.

12A Around this time of the year?

$13 \mathrm{~S}$ Because [

14A [We're $\uparrow$ dead[

15P [Let's just thank God for ability to feed and clothe [ $\uparrow$ that's most important

$16 \mathrm{~S} \quad[\uparrow$ Yes ooo $\neq$

$17 P \quad Y e a h \downarrow$

18P ${ }^{\circ}$ God save us ${ }^{\circ}$

19A I think (.) we must all go into farming [

20P [I bet you ooo $\uparrow$, to supplement our meager salaries (1) with n:plenty responsibilities if not,n:hmmm

$21 S<n: B e c a u s e$ last time > [

22A [I have come to believe that salary alone (.) cannot change one's life

23A Right?

24S Sure $\downarrow$

25 A My $\downarrow$ rent will be expiring in December, just ima:gine $\neq$

26S Just paid mine two months ago $\downarrow$

27A That's another $\uparrow$ problem...I don't $\downarrow$ know (4) when I will complete my building

$28 \mathrm{~S}$ Ahaa, have you resolved your plot issue?

29 Phere?=but me I'm building, they should come demolish it

$30 \mathbf{P}$ We are tired with landlords=

31P $=\downarrow$ Abaaa!

$32 \mathbf{P}$ n:Today this, tomorrow that [

33A $\quad[$ As if a tenant is always a homeless person [oh nooo

$34 \mathrm{~S} \quad[\mathrm{Oh} \downarrow$

35P (unclear) we all have homes(.) somewhere $\neq$

36A But who cares? (2)

37P No, but a few landlords are reasonable

38 Ah have we paid all our drinks?=

39P $=\uparrow$ No!

$40 \mathrm{~S}$ How much is left?=

41P $=\uparrow$ Yes!emmm

42S Please add this... $\uparrow$ !

43P You returned from funeral yesterday, so relax

44A Oh yea, please $\uparrow$ pick your money $\downarrow$

45P $[\downarrow$ Yeah, yeah $\uparrow$

46P I $\uparrow$ know you are fucking loaded but another day

47S Oh really? hahahah, [ you $\downarrow$ know

48P [We even needed to a:ccompany you, [because of the WASSCE invigilation

49S Sure[

50P n: hello... seller....

51S Well, can't really say any:thing again (collecting back money from table)=

52P $=$ relax bro $\downarrow$

53S [God con:tinue to bless our friendship[

54A Amen $=\downarrow$

55S $=$ Yeah

56A ${ }^{\circ}$ God dey ${ }^{\circ}(3)$

57S [laugh] 
58S Sure $=$ it shall be well $\neq$

59A $=$ small, small $=$

Transcription of Second Conversation (Marriage) (Lasting 4 Minutes, 13 Seconds)

60S $=\ldots$..school fees (2) meanwhile she is also working hmmh..why?

61A n:hahahahaahahahaa $\uparrow m m m . . \neq \neq$

62S Is that how they are ${ }^{\circ}$ everywhere $\uparrow$ ?

63P <me I just ignore them some:times> why? (2) unfortunate[ man ${ }^{\circ}$ always to blame

64S [As for my wife(.) it's too much (2) I don’t get it $\uparrow$ [too many demands

65A [个Don't go there my brother [laugh]

66P Freedom [laugh] that's what they call it

67S $[$ laugh] $\uparrow$ interesting $\neq$

68P Yeah [end of laugh] freedom

69A $\uparrow$ Freedom now means spousal ex:ploitation..

70P Sure $\uparrow$ Together[laugh]

71S Well... $<$ we will manage them like that $>^{\circ}$,

72P Problems everywhere $=$

73A =And problems of their fa:milies become your pro:blems too

74S Oh yeah $\uparrow$ but problems of your family are not her problems, nooo $\uparrow$

75P The good thing is that(.) you are not obliged...do what you can

76S n:Exactly my philosophy too..let them talk $\neq$

77P Last year I asked mine to add just GHC 200 to pay our rent.

78A $\mathrm{Hmmm} . . \neq$

79P She told me that her fa:ther has many houses $\uparrow$

$80 S$ Whaaa...t! (hands on head)

81P $\uparrow \underline{\text { Only God }=}$

82A $=\uparrow \underline{Y e a: h=}$

83S Ya

84A So just do what you can that's all (3)

$\mathbf{8 5 S}<$ we are in for trouble>

86P Yeah [laugh]

87S Ooh! (.) mine [laugh]

88A That's the $\uparrow$ problem [laugh] Together[laugh] (2)

89A So (3) we have to be very patient. But for how $\uparrow$ lo:ng?

90A How much is enough? The more you tolerate(.) the more they mis:behave

915 Because [

92A [It's $\uparrow$ difficult [

93P [So just keep your ba:lance [ $\uparrow$ blow hot and cold

94S [个Aha...so try to be firm and a bit loose(.) at the same time

95P Yeah

96P $\quad{ }^{\circ}$ So you must look funny $\uparrow$ as a hus:band ${ }^{\circ}$ [laugh]

97A But you will have the [

98P [The children suffer sadly (1) nawaoo......

99S <Because last time > [

100A [Noo,chil:dren will get to under:stand

101A $\uparrow$ Right?

102S ${ }^{\circ}$ Right $^{\circ}$

103A Because as they grow(.) they get to understand that Daddy was not being wicked $\neq$

104S Yeah,...problem here is that they try to change their minds too $\downarrow$ against you..

105A That's the $\uparrow$ problem...I don't $\downarrow$ know (4) 


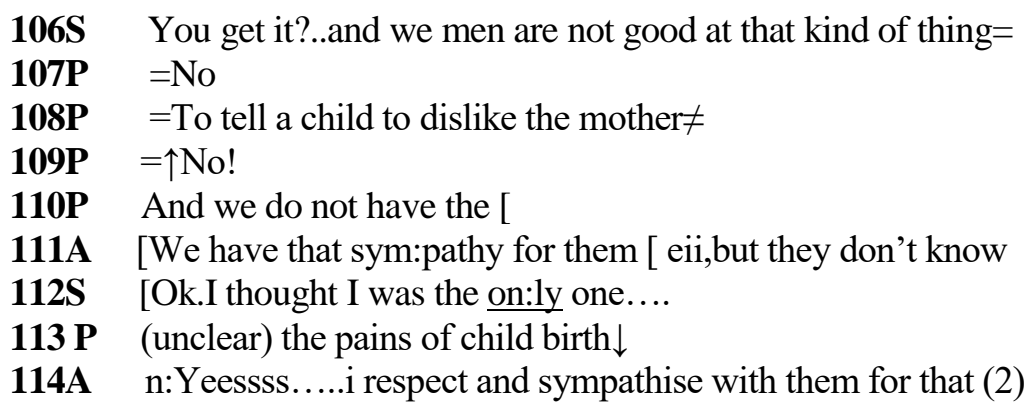

Transcription of Third Conversation (Politics) (Lasting 3 Minutes, 41 Seconds)

115P ...this year dieee......

$116 \mathrm{~S}$ So is NDC can:celling FREE SHS ?=

$117 \mathrm{P}=\uparrow \underline{\text { No}}$ !

$118 S$ They will maintain it?=

$119 P=\uparrow$ Yes!

$120 S$ Oh..that's $\uparrow$ interesting!

121P Extending it to even private schools

122A ....and vo:cational institutions $=$

123P $[\downarrow$ Yeah, yeah

124P I know $\downarrow$

125S But we can judge (.) from our own experiences, [ you $\downarrow$ know

126P [But who $\uparrow$ do we trust now? NDC or NPP? $\uparrow$

127S mm..well (2) debatable! What's exactly their aim? Getting votes?

$128 \mathrm{P}$ Ultimately so $\uparrow$

129S And then how (.) can they achieve these plenty pro:mises? [

130A [The manifesto itself $=$

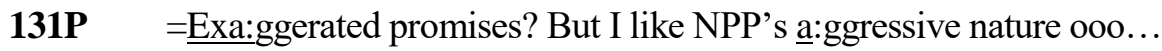

132 At least man must dream big! [ Over 600 promises in 2016

133A [And even more this time around $\downarrow=[$ laugh]

134S $=$ Yeah $\neq$

135A ${ }^{\circ}$ eiii power... ${ }^{\circ}(3)$ [

136S As for FREE SHS it's a good thing= Mahama dare not touch it... ehm

$\uparrow$ scrap it and see... ${ }^{\circ}$ wo be ti bobolibobo ${ }^{\circ}=[$ laugh $]$

137A =in:fact I admire that party (.) for their brave policies=

$138 \mathrm{~S}=$ =eah sure (2) just look at health in:surance who plays with health?

139A Their main cha:llenge as a party...(unclear)... $\neq$

140P [NDC too has done well on infras.....

141A ...the control by some few people at the top. That's NPP problem

142S ${ }^{\circ}$ power struggle [

143P <Gha:naians are now wise ooo $>$ they want results [about ${ }^{\circ}$ not mere promises ${ }^{\circ}$

144S [Sure (2) poli:ticians must know this....the [

145A [个Independence

146P Freedom [laugh]

147S [laugh] interes:ting

148P Yeah $\downarrow[$ you can:not force peo:ple to follow you $\neq$

149A $\uparrow$ Freedom!...[laugh] (3)

150P Gone are the days... To:gether [laugh]

$151 S \quad W e l 1 . .{ }^{\circ}<$ fear dele:gates [laugh] $>^{\circ}$, oh my God! ..Sir John!

152P $\mathrm{Hmmm} \downarrow=$ one fine poli:tician ooo.

153A $=$ n:Oh yeah=he doesn't insult(.) opponents.. but full of hu:mour 
154S What can we do? God knows best...

$155 P Y$ Yah $\downarrow$, now that there is n:plenty food on the table,he is gone[

156S $=$ That's God for you $\downarrow[$ He says our ways are not his ways $\neq$

\section{Phase II: Responding to Research Questions based on Transcribed Data}

Research Question 1: What are the Recurring Patterns of Interaction in Informal Conversations?

\&

Research Question 3: How do Recurring Patterns of Interaction Play out in Informal Conversations?

NB: The two Research Questions above are analysed and discussed together due to their closely related nature. We find it more convenient and appropriate to identify the occurrences of recurring patterns and indicate thereof, how those recurring patterns manifest themselves in the transcribed conversations, rather than separate the two. Research question 2 is not so closely related, hence the isolated analysis of it.

\section{$\underline{\text { Analysis }}$}

The ensuing discussion provides answers to the two research questions above. There is no conversation without turn-taking. Ochs (1979) defines a turn as "...an utterance bounded by significant pause or by utterance of other participants". In other words, a turn is the speech of one person continued until another takes the floor. An adjacency pair is a sequence of two related utterances by two different speakers. The second utterance is a response to the first. It is a particular type of turn taking structure. Throughout the three conversational pieces, turn-taking inevitably exists as a recurring pattern. Adjacency pairs, as can be seen in Table 1, play a very great role in terms of turn-taking in these series of conversations. This spans from the pairs of utterances $1 \mathrm{P} / 2 \mathrm{~S}$ through $23 \mathrm{~A} / 24 \mathrm{~S}, 40 \mathrm{~S} / 42 \mathrm{P}, 66 \mathrm{P} / 67 \mathrm{~S}$, $81 \mathrm{P} / 83 \mathrm{~S}, 118 \mathrm{~S} / 119 \mathrm{P}$, etc., to $155 \mathrm{P} / 156 \mathrm{~S}$ (just to mention a few). As explained already, an adjacency pair is a sequence of two related utterances by two different speakers. The second utterance is a response to the first. In all these pairs therefore, a first turn-taker usually says something which is reacted to somehow by a second turn-taker. In 1P/2S for instance, the second turn-taker 2S's expression "Hmmm..." is a reaction or response to 1P's utterance "Cheap $\uparrow$ are you not in Gha:na?" Moving on, 79P's utterance "She told me that her fa:ther has many houses $\uparrow "$ is reacted to or relates with 80 S's response "Whaaa...t! (hands on head)". The same can be said of the remaining 42 pairs of utterances as shown in Table 1.

Secondly, one recurring pattern in the series is topic change. Though not very regularly recurrent relative to the other tenets under consideration, this major tenet of CA occurs in utterances $38 \mathrm{~S}, 50 \mathrm{P}$ and $151 \mathrm{~S}$, across the three recordings. In utterance $38 \mathrm{~S}$, the change in topic was from the Economy to the question of whether all the drinks on the table had been paid. These are two unrelated matters to the extent that the speaker deflected from the main subject of discussion which was the Economy to enquire if they owed the pub as of the time of the enquiry. In 50P, the speaker again deflected from the Economy into calling the pub attendant. And finally in $151 \mathrm{~S}$, the speaker changes topic from Politics in general to talk about a personality in Ghanaian Politics (known as Sir John).It must be noted that, 
much as there seem to be some relatedness, the conversation took a totally different dimension after this particular utterance. The conversation dived from general political issues to the personality traits of a deceased politician. So the change is one from politics to the character.

The third recurring pattern revealed in this analysis is Figurative Language. In 155P, the expression "...plenty food on the table.." depicts symbolism within the context. The speaker means to underscore the fact that the deceased's party is currently in power and therefore, if he was alive he would have enjoyed power too. Therefore, food is used to represent power symbolically. The second figurative device used in the recordings is rhetorical question. This is a question that does not really demand an answer or is meant to emphasise a point. This is manifest in 1P, 29P, 60S, 62S, 89A, 90A and 127S.

Fourth and finally, dysfluency is another recurrent pattern in the conversations. From the review of literature earlier in this work, Dysfluency often takes place in an informal situation in social interaction. The more informal the conversation is, the more frequently it happens. It could be symbolized by providing unfinished sentences, repeating words, or even repeating parts of sentences. This scenario is clearly manifested in $2 \mathrm{~S}, 50 \mathrm{P}, 60 \mathrm{~S}, 61 \mathrm{~A}, 78 \mathrm{~A}, 115 \mathrm{P}, 135 \mathrm{~A}, 139 \mathrm{~A}$ and $140 \mathrm{P}$. Among the variables listed above which determine dysfluency in a conversational piece, unfinished sentences is the predominant variable as far as the three recordings are concerned. It occurs in all the utterances listed above as in "Hmmm...", "infras...," etc. They generally do not really express complete thoughts within the contexts in which they occur.

Research Question 2: Which recurring patterns of interaction dominate in informal conversations?

$\underline{\text { Analysis }}$

From the analysis of data in Phase 1 of Data analysis above, the frequency tallies for the four recurrent patterns in these conversations have been summarised in Table 1. Clearly, Adjacency pairs is the most dominant with a total tally of 44 pairs across the three conversations. This is followed distantly by Dysfluency with a tally ratio of 9. Dysfluency is closely followed by Figurative Language with total tally of 8 and finally Topic Change with a total tally of 3 (see Table 1). 
Table 1. Frequency Distribution of Recurring Patterns

\begin{tabular}{|c|c|c|c|c|c|c|}
\hline & \multicolumn{2}{|c|}{ Adjacency Pairs } & $\begin{array}{c}\text { Topic } \\
\text { Change }\end{array}$ & $\begin{array}{l}\text { Figurative } \\
\text { Language }\end{array}$ & Dysfluency & \\
\hline & $1 \mathrm{P} / 25$ & $94 \mathrm{~S} / 95 \mathrm{P}$ & $38 \mathrm{~S}$ & $1 \mathrm{P}$ & $2 \mathrm{~S}$ & \\
\hline & $3 \mathrm{P} / 4 \mathrm{~A}$ & $98 \mathrm{P} / 100 \mathrm{~A}$ & $50 \mathrm{P}$ & $60 \mathrm{~S}$ & $50 \mathrm{P}$ & \\
\hline & $3 \mathrm{P} / 5 \mathrm{~S}$ & $101 \mathrm{~A} / 102 \mathrm{~S}$ & $151 \mathrm{~S}$ & $62 \mathrm{~S}$ & $60 \mathrm{~S}$ & \\
\hline & $10 \mathrm{~A} / 11 \mathrm{~A}$ & $104 / 105 \mathrm{~A}$ & & $29 \mathrm{P}$ & $61 \mathrm{~A}$ & \\
\hline & $15 \mathrm{P} / 16 \mathrm{~S}$ & $116 \mathrm{~A} / 112 \mathrm{~S}$ & & $89 \mathrm{~A}$ & $78 \mathrm{~A}$ & \\
\hline & $15 \mathrm{P} / 17 \mathrm{P}$ & $113 \mathrm{P} / 114 \mathrm{~A}$ & & $90 \mathrm{~A}$ & $115 \mathrm{P}$ & \\
\hline & $23 \mathrm{~A} / 24 \mathrm{~S}$ & $116 \mathrm{~S} / 117 \mathrm{P}$ & & $127 \mathrm{~S}$ & $135 \mathrm{~A}$ & \\
\hline & $35 \mathrm{P} / 36 \mathrm{~A}$ & 118S/117P & & $155 \mathrm{P}$ & $139 \mathrm{~A}$ & \\
\hline & $38 \mathrm{~S} / 39 \mathrm{P}$ & $119 \mathrm{P} / 120 \mathrm{~S}$ & & & $140 \mathrm{P}$ & \\
\hline & $40 \mathrm{~S} / 43 \mathrm{P}$ & $121 \mathrm{P} / 122 \mathrm{~A}$ & & & & \\
\hline & $46 \mathrm{P} / 47 \mathrm{~S}$ & $121 \mathrm{SS} / 123 \mathrm{P}$ & & & & \\
\hline & $48 \mathrm{P} / 49 \mathrm{~S}$ & $127 \mathrm{~S} / 128 \mathrm{P}$ & & & & \\
\hline & $53 \mathrm{~S} / 54 \mathrm{~A}$ & $132 \mathrm{~S} / 133 \mathrm{~A}$ & & & & \\
\hline & $60 \mathrm{~S} / 61 \mathrm{~A}$ & $133 \mathrm{~A} / 134 \mathrm{~S}$ & & & & \\
\hline & $64 \mathrm{~S} / 65 \mathrm{~A}$ & $137 \mathrm{~A} / 138 \mathrm{~S}$ & & & & \\
\hline & $66 \mathrm{P} / 67 \mathrm{~S}$ & $143 \mathrm{P} / 144 \mathrm{~S}$ & & & & \\
\hline & 69A/70P & $151 \mathrm{~S} / 152 \mathrm{P}$ & & & & \\
\hline & $73 \mathrm{~A} / 74 \mathrm{~S}$ & $152 \mathrm{P} / 153 \mathrm{~A}$ & & & & \\
\hline & $75 \mathrm{P} / 76 \mathrm{~S}$ & $154 \mathrm{~S} / 155 \mathrm{P}$ & & & & \\
\hline & $79 \mathrm{P} / 80 \mathrm{~S}$ & $155 \mathrm{P} / 156 \mathrm{~S}$ & & & & \\
\hline & $81 \mathrm{P} / 82 \mathrm{~A}$ & & & & & \\
\hline & $81 \mathrm{P} / 83 \mathrm{~S}$ & & & & & \\
\hline & $85 \mathrm{~S} / 86 \mathrm{P}$ & & & & & \\
\hline & 93P/94S & & & & & \\
\hline To & 44 & & 3 & 8 & 9 & 64 \\
\hline Total & 68.8 & & 4.7 & 12.5 & 14.0 & 100 \\
\hline
\end{tabular}

The tallies in Table 1 are graphically represented in the Bar Chart in Figure 1.

Figure 1. Frequency Distribution of Patterns

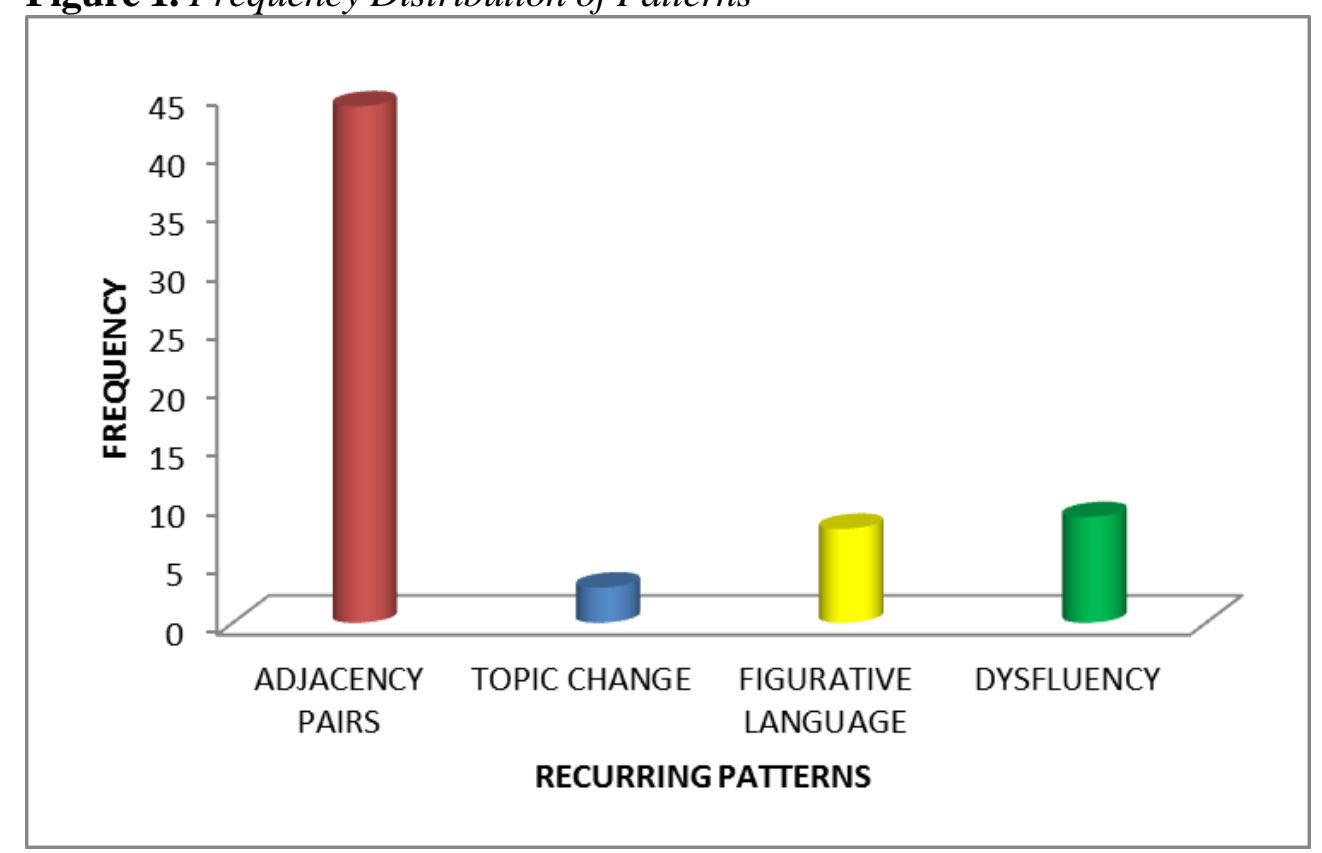


In terms of percentage distribution, the tallies are further represented in the Pie Chart in Figure 2.

\section{Figure 2. Percentage Distribution of Patterns}

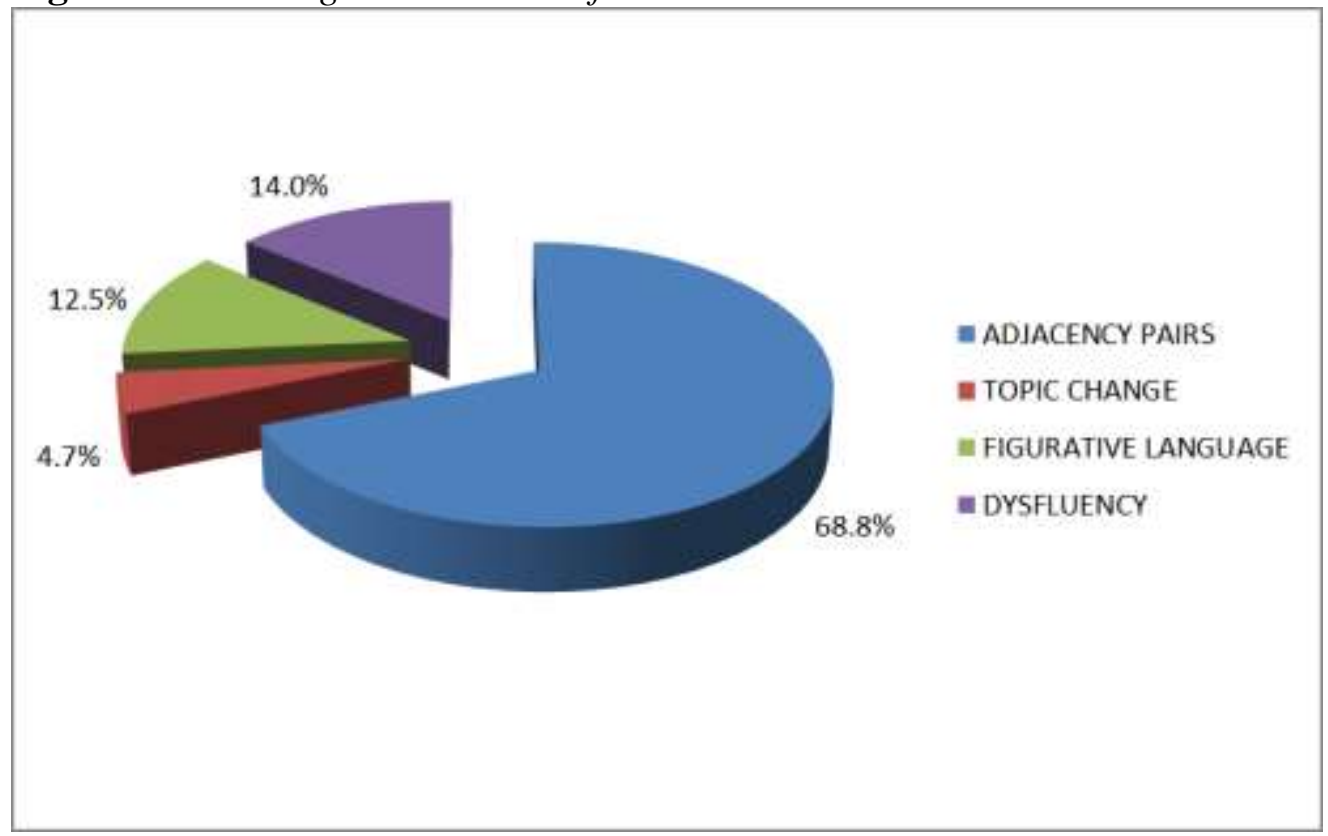

\section{Discussion}

It is worthy of note that the nature and procedure of the analysis of data in this study embodies both the analysis and discussion of the results concurrently. Any further attempts to discuss findings may result in mere duplications, repetitions and redundancies. We therefore take you straight to the conclusions drawn from the study.

\section{Conclusion}

From the foregoing analysis and discussion of results, three conclusions can be drawn based on the three research questions in this study. The analysis reveals that four main recurring patterns characterize informal conversations among friends: Adjacency Pairs, Topic Change, Figurative Language and Dysfluency. This answers Research Question 1. For Research Question 2, Table 1 clearly outlines the overwhelming dominance of Adjacency pairs as a form of turn-taking over the other three recurring patterns. One may thus conclude that adjacency pairs dominate in informal conversations among participants who are friends. It may also be concluded, for Research Question 3 , that friendly informal conversations stay focused on selected topics, driven by close adjacency pairs, riddled with dysfluencies and tied together by rhetorical questions with very little propensity towards topic change. 


\section{References}

Atkinson M, Heritage J (1984) Structures of social action: studies in conversation analysis. Cambridge: Cambridge University Press.

Beattie G (1983) Talk: an analysis of speech and non-verbal behavior in conversation. London: Open University Press.

Brown P, Levinson SC (1978) Politeness: some universals in language use. Cambridge: Cambridge University Press.

Davis LE (1984) Ethnicity in social group work practice. New York: Haworth Press.

Frohlich DM, Luff P (1989) Conversational resources for situated action. In Wings for the Mind. Proceedings of the SIGHI Conference on Human Factors in Computing System (pp. 253-258).

Fussel SR, Kreuz RJ (1998) Social and cognitive approaches to interpersonal communication. Mahwah, NJ: Lawrence Erlbaum Associates.

Havey PT (1999) Doing conversation analysis: a practical guide. London: SAGE Publications Ltd.

Hepburn A, Bolden GB (2017) Transcribing for social research. SAGE Publications Ltd.

Heritage J, Greatbatch D (1986) Generating applause: a study of rhetoric and response at party political conferences. American Journal of Sociology 92(1): 110-157.

Hoey ME, Kendrick KH (2017) Conversation Analysis. In AMB De Groot, P Hagoort (eds.), Research Methods in Psycholinguistics and the Neurobiology of Language: A Practical Guide, 151-173.

Holtgraves T (1992) Language and face-work. Social Psychology Quarterly 5(2): 141159.

Hutchby I, Wooffitt R (1998) Conversation analysis: principles, practices and application. Cambridge: Polity Press in Association with Blackwell Publishing.

Jefferson G (1972) Side Sequencers. In DN Sudnow (Ed.) Studies in Social Interaction, 294-333. New York, NY: Free Press.

Leech G (1981) Semantics: the study of meaning. $2^{\text {nd }}$ Edition. Harmondsworth: Penguin Books.

Levinson CS (1983) Pragmatics. Cambridge: Cambridge University Press.

Mey J (2001) Pragmatics: an introduction. Oxford: Blackwell Publishing.

Mondada L (2019) Contemporary issues in conversation analysis: embodiment and materiality, multimodality and multisensoriality in social interaction. Journal of Pragmatics 145: 47-62.

Nur A (2014) Classroom Related Talk: Conversation Analysis of Asian EFL Learners. Journal of Language, Education, and Humanities 2(1).

Ochs E (1979) Planned and unplanned discourse. In T. Givon (ed.), Syntax and Semantics. New York: Academic Press.

Sacks H (1972) On the analyzability of stories by children. In JJ Gumperz, D Hymes (eds.), Directions in Sociolinguistics: The Ethnography of Communication, 325-345. New York: Rinehart \& Winston.

Sacks H (1992) Lectures on Conversation. Oxford: Blackwell Publishing.

Seedhouse P (2004) The interactional architecture of the language classroom: a conversation analysis perspective. Malden, Mass: Blackwell.

Wardhaugh $\mathrm{R}$ (2006) An introduction to sociolinguistics. $5^{\text {th }}$ Edition. Blackwell Publishing.

Wooffitt R (2001) Discourse as data: a guide for analysis. London: SAGE Publications Ltd. 
Yule G (2010) Pragmatics. Oxford: Oxford University Press.

Yun CC (2006) Preserving students' face in foreign language teaching. Sino-US English Teaching 3(12): 45-47.

\section{Appendix}

Symbols

\begin{tabular}{ll}
$()$. & Short pause \\
$:$ & Prolonged pronunciation/sound \\
$(\neq)$ & Longer pause \\
$(2),(3)$, etc. & Repeated action \\
& \\
\hline Sounds & Stressed words \\
\hline & Overlap (point when the next utterance interrupts) \\
$\uparrow$ & No gap between two utterances \\
$\downarrow$ & Higher voice pitch \\
{$[$ laugh $]$} & Lower voice pitch \\
n: & Nonverbal feature \\
$<$ speech> & Long sound \\
${ }^{\circ}$ speech & Fast speech \\
$\ldots$ & Quiet speech \\
$1,2,3,4,5$, etc. & Elliptical expressions \\
$\mathrm{P}, \mathrm{S}, \mathrm{A}$ & Numbering/labelling of utterances
\end{tabular}

NB: The numeral-letter tags are meant to give unique identification to each utterance for ease of reference. 
